\title{
Possibilidades de Uso da Impressora 3D em Projetos de Sala de Aula
}

\author{
Marilei de Fátima Kovatlii ${ }^{1}$, Andressa Kotz ${ }^{1}$, Ederson Luiz Locatelli ${ }^{2}$ \\ ${ }^{1}$ LABTEC - Laboratório de Tecnologias - Colégio Marista Santo Ângelo - RS \\ Av. Venâncio Aires - Santo Ângelo - RS, 98801-660. \\ ${ }^{2}$ Rede Marista - RS \\ R. Irmão José Otao, 11 - Bom Fim, Porto Alegre - RS, 90035-060 \\ \{marilei.kovatli, andressa.kotz, ederson.locatelli\}@ maristas.org.br
}

\begin{abstract}
This article details activities undertaken with a $3 D$ printer in educational projects in basic education, starting from early childhood education. The growing availability of $3 D$ printing technology created opportunities for exploration in new areas like education. This study is substantiated by the fact that the insertion of information and communications technology (ICT) inside the educational space is becoming a reality and it is contributing to the learning experience. It is showing ways of making formal education more attractive and interactive. This experience allowed the observation and applicability of $3 D$ printing technology in the educational projects context.
\end{abstract}

Resumo. Este artigo, caracterizado como relato de experiência, descreve atividades realizadas com a impressora $3 D$ em projetos educativos na educação básica, a partir da Educação Infantil. A crescente disponibilidade da tecnologia de impressão 3D abriu oportunidades de explorações em novas áreas, como a educação. O estudo justifica-se considerando que a inserção das tecnologias digitais da informação e comunicação (TDIC) no espaço escolar vem tornando-se realidade e contribuindo para a aprendizagem, tornando a educação mais atrativa e interativa. A experiência permitiu observar a aplicabilidade da tecnologia de Impressão $3 D$ no contexto de projetos educativos.

\section{Introdução}

A tecnologia cresce de maneira exponencial, e está inserida em vários segmentos da sociedade, inclusive na educação. A nova geração de alunos nasce e cresce num mundo amplamente digital, cercada por dispositivos e artefatos tecnológicos e com informação constantemente atualizada.

Pesquisas em todo o mundo mostram a importância de tornar o sistema de ensino cada vez mais dinâmico e interessante para os alunos. As tecnologias digitais têm proporcionado reconfigurar o modelo tradicional das práticas pedagógicas, o qual era caracterizado majoritariamente feito de longas exposições teóricas dos professores diante de dezenas de alunos. Contudo, novas possibilidades são possíveis com as tecnologias digitais, as quais incluem atividades práticas e experiências cotidianas, que envolvem os estudantes, a fim de tornar o processo mais eficiente e o aprendizado mais 
completo. Dessa maneira, a utilização das TDIC (tecnologias digitais de informação e comunicação) vem se fazendo cada mais presente na educação como meio de possibilitar a integração da tecnologia com os processos de ensino e de aprendizagem [Mercado, 2002].

Neste cenário, onde a tecnologia está ocupando um espaço cada vez maior, a educação busca desenvolver estratégias e metodologias para utilização dos recursos of ertados no ensino e aprendizagem em sala de aula. Assim, entende-se que a escola precisa criar desafios para que as crianças possam utilizar as tecnologias de forma criativa [Gagné, 1971]. Este contexto dá origem ao problema desta pesquisa, que é apresentar quais as possibilidades de uso da impressora 3D em projetos educativos.

Diante disso, o artigo tem como objetivo geral demonstrar atividades práticas na impressora 3D que podem ser inseridas em projetos educativos, envolvendo alunos a partir da educação infantil e nas séries iniciais do ensino fundamental. Desta forma, os objetivos específicos foram definidos como: identificação das necessidades e possibilidades de ensino e aprendizagem mediados pela tecnologia em questão; desenvolvimento do plano de construção do instrumento didático desejado; modelagem 3D do objeto utilizando softwares de desenho ou buscando por modelos prontos; preparação e impressão do modelo $3 \mathrm{D}$ na impressora $3 \mathrm{D}$; utilização e avaliação do objeto real gerado.

O artigo está organizado da seguinte forma: na seção 2 de "Desenvolvimento" aborda-se a utilização da tecnologia na educação e suas especificações técnicas. $\mathrm{Na}$ seção 3, apresenta-se a metodologia utilizada durante o desenvolvimento do estudo. $\mathrm{Na}$ sequência, a seção 4 apresenta e discute os resultados obtid os e as considerações finais. Por fim, são apresentadas as referências bibliográficas que nortearam o embasamento teórico do estudo em questão.

\section{Impressora 3D: processos e produtos}

A impressão 3D é uma tecnologia que possibilita transformar a maneira com que desenvolvemos nossos produtos, estand o presente em diferentes áreas e contextos: Engenharia, Arquitetura, Comércio, Sustentabilidade e também na Educação, que é o foco deste artigo. Primeiramente, a impressão 3D é um processo onde um modelo digital tridimensional que está em um computador é criado fisicamente pela deposição de sucessivas camadas de material [Relvas, C. A. M., 2018]. Define-se um objeto, utilizando um software para criá-lo de maneira tridimensional (3D), especificam-se suas dimensões e, através da fusão e deposição do filamento PLA (Ácido Polilático) pode-se imprimir fisicamente o objeto desenvolvido no computador.

A impressora 3D utilizada no projeto faz parte da empresa Cliever e seu modelo é o Cliever CL-1 Black Edition. Esse modelo específico conta com algumas tecnologias interessantes, como o aquecimento da superfície de impressão, que pode chegar a 100 graus Celsius e o seu painel de controle independente, com o qual pode ser feita toda a configuração de impressão [CLIEVER 2019]. O seu bico extrusor tem a capacidade de atingir 250 graus Celsius, o que garante um controle e qualidade maior do objeto a ser impresso, dependendo do pigmento do filamento utilizado. A empresa Cliever conta com seu próprio software, Cliever Studio 5.0, e é através dele que se redimensiona o objeto e ajusta-se todas as configurações. Nele também é possível acompanhar e gerenciar todos os processos da impressão.

Existem vários tipos de filamentos para impressão 3D, porém, o optado para ser 
utilizado em nossas impressões é o PLA devido ao fato de proporcionar peças com boa qualidade e segurança, trazendo maior fidelidade ao modelo desenvolvido na plataforma, além de não ser tão rígid o quanto outros tipos de filamentos, como o ABS [Relvas, C. A. M., 2018]. O PLA trata-se de um poliéster termoplástico, produzido a partir de fontes naturais como o milho e a cana de açúcar, o que o torna um material biodegradável e, dessa maneira, demonstrando um dos muitos benefícios que se pode ter com esse tipo de serviço. Em sua forma natural ele é translúcido, porém, com a utilização de pigmentos, é possível obter as mais variadas cores de filamentos para as impressões. A escola, recentemente, adquiriu diversos rolos de filamentos coloridos para proporcionar uma fidelidade maior aos objetos impressos.

\section{Metodologia}

A metodologia das atividades se deu através de vários projetos em conjunto com as professoras regentes de cada uma das turmas envolvidas. Neles, foram pensados e elaborados planos de ensino onde a tecnologia da Impressora 3D pudesse ser inserida. O uso desses equipamentos revolucionará os ambientes de ensino, trazendo um novo conceito de recurso didático, que torna o aprendizado mais interativo e dinâmico, otimizando o papel do professor [Mercado, 2002]. Quanto ao aluno, o incentivo ao aprendizado só aumenta mediante a apresentação de desafios que o aproximem da vida real na qual aquele conhecimento poderá ser aplicado.

A primeira experiência de introdução da tecnologia de impressão 3D no contexto educacional se deu através do projeto "Como vivem as minhocas", desenvolvido com alunos da educação infantil. Inicialmente, eles realizaram uma pesquisa, com auxílio da professora regente, sobre as minhocas e como vivem. Em seguida assistiram um vídeo sobre o assunto e, por fim, acompanharam o processo de impressão 3D de minhocas, que se deu pela pesquisa da modelagem 3D na ferramenta online Tinkercad, após, seu redimensionamento no software Cliever Studio e posterior impressão.

O segundo e o terceiro projetos, igualmente à primeira experiência, foram aplicados na educação infantil, tendo como tema, respectivamente, "Os animais do jardim" e "Borboletas que voam". Os alunos realizaram pesquisas referentes aos temas abordados. O primeiro grupo escolheu os animais a serem impressos e acompanharam o processo de produção. O segundo grupo de alunos identificou as partes do ciclo da borboleta e acompanhou a impressão do ovo inteiro, do ovo quebrado, da lagarta, do casulo e, por fim, da borboleta. Em seguida, eles foram desafiados a colocar cada um dos objetos na ordem correta. As figuras 1, 2, 3 e 4 representam as etapas do projeto das borboletas, demonstrando a realização da pesquisa nos computadores do laboratório e nos livros da biblioteca e, em seguida, acompanhando o processo de impressão dos modelos 3D escolhidos. Por fim, os alunos realizaram uma atividade que consistia em completar corretamente o ciclo da borboleta utilizando os objetos impressos. 


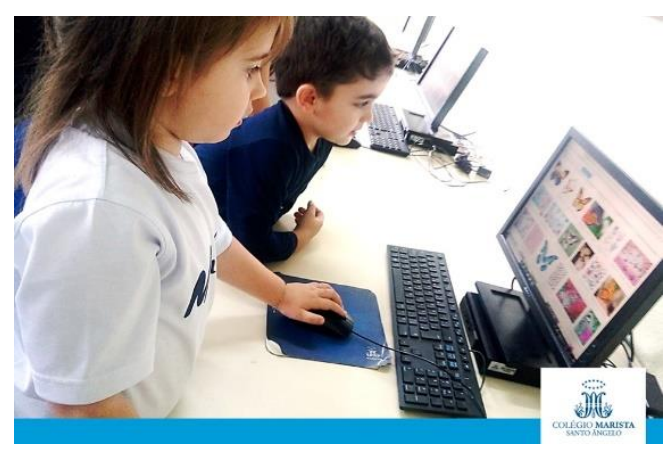

Figura 1. Pesquisa no computador

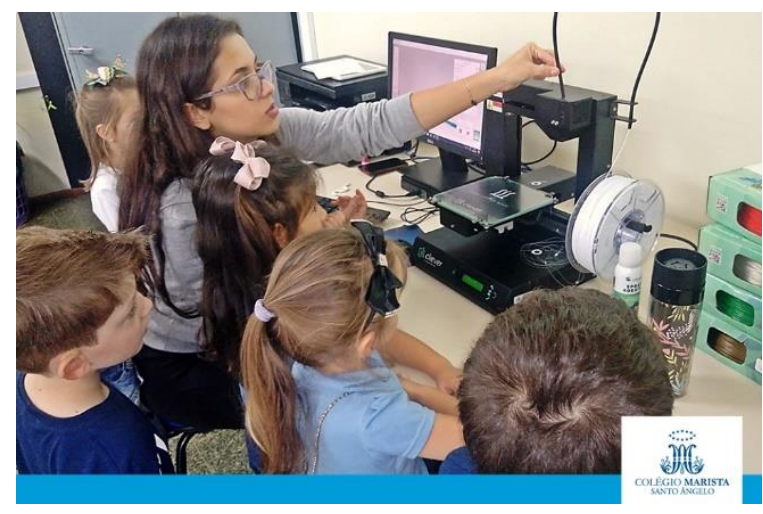

Figura 3. Aprendendo o processo

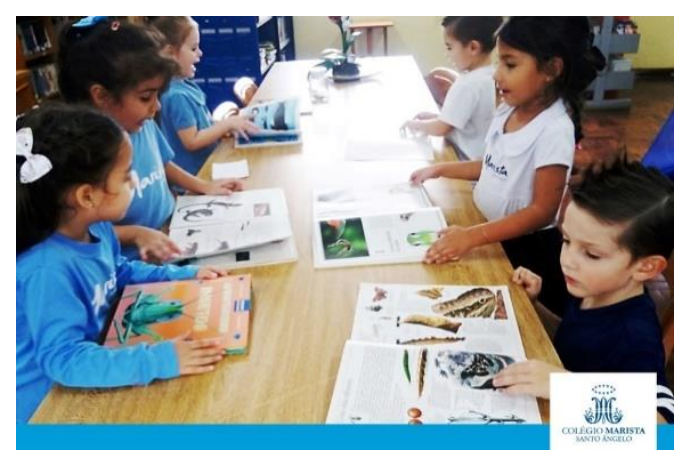

Figura 2. Pesquisa na biblioteca

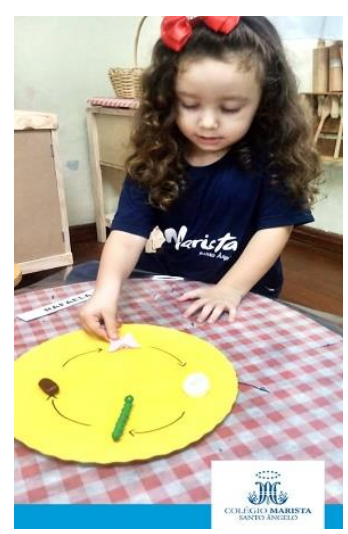

Figura 4. Atividade prática

Com uma turma de alunos do $2^{\circ}$ ano do Ensino Fundamental, a tecnologia foi inserida através do projeto "Quem canta, encanta o Brasil", onde os alunos estudaram os instrumentos musicais e os diversos grupos em que estavam inseridos. A próximo passo desse projeto foi definir quatro instrumentos a serem impressos na impressora 3D, e eles foram os seguintes: flauta, tambor, violão e guitarra. Após, os alunos acompanharam as etapas da impressão 3D, desde escolher o modelo 3D ideal até a geração das rotas de impressão e posterior impressão.

A última atividade de inserção da impressora 3D foi uma sequência didática, cujo tema era "Cadeia Alimentar, o que é?", na qual os alunos estudaram, em sala de aula, a cadeia alimentar e, após, acompanharam, em grupos, a impressão 3D dos seguintes elementos dos níveis que compõe a cadeia alimentar: produtor, consumidor primário, consumidor secundário, consumidor terciário, consumidor final e produtor. Suced eu-se a impressão de cinco objetos de cad a nível da cadeia. No final desse estudo, os alunos foram desafiados, nos mesmos grupos definidos anteriormente, a organizar os elementos conforme estudaram. A figura 5 mostra cinco cadeias construídas na impressora 3D durante o projeto e a figura 6 demonstra uma atividade desenvolvida utilizando os modelos da cadeia alimentar. Essa atividade consistiu em criar cinco grupos de alunos, sendo que um aluno por grupo poderia pegar um único modelo de cada vez. Ao terminarem os modelos, o desafio era conseguir montar uma cadeia alimentar, se não fosse possível, os grupos poderiam trocar uma peça por vez entre eles, para novamente tentar completar o desafio. 


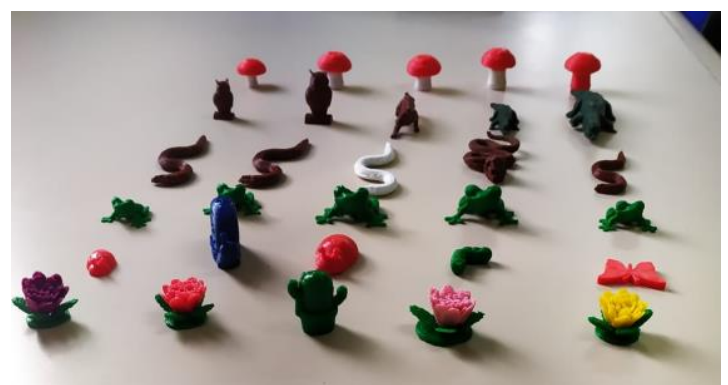

Figura 5. Cadeia alimentar 3D

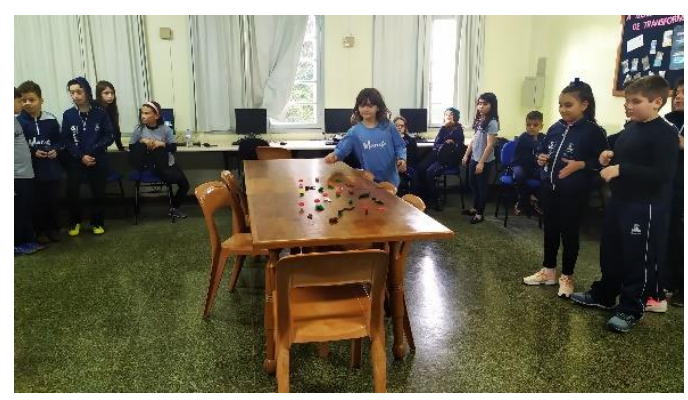

Figura 6. Atividade prática em grupo

Na primeira vez que a atividade foi realizada, nenhum grupo conseguiu completar a cadeia alimentar, então partiram para a segunda parte do desafio, que era trocar os modelos entre os grupos. Depois de completarem o desafio, os grupos precisaram explicar os componentes de sua cadeia alimentar.

Em todas as atividades realizadas foi possível observar a admiração dos alunos diante da impressora 3D, novidade para a maioria. Além disso, constatou-se que o aprendizado realmente se deu de maneira mais intensa com a utilização dessa tecnologia na educação, devido ao fato de que a impressão 3D oferece ao aluno escolher ou modelar um objeto de maneira digital e, posteriormente, ter a oportunidade de manuseá-lo fisicamente

\section{Conclusão}

É fácil perceber que as possibilidades de aplicação da tecnologia de impressão 3D na educação são quase infinitas. Escolas podem e devem avaliar quais são as que mais se adequam às demandas específicas, à intencionalidade pedagógica e se preparar para a reconfiguração das práticas pedagógicas considerando os sujeitos da aprendizagem.

Em uma sociedade que exige cada vez mais de seus indivíduos e pensando em um mercado de trabalho extremamente competitivo, é essencial oferecer as melhores condições de aprendizado para que os alunos desenvolvam competências e, assim, se diferenciem e conquistem o seu espaço [Gagné, 1971]. Além disso, eles podem se tornar profissionais preparados, competentes e com muito a oferecer para a sociedade. É com essa proposta que buscamos incorporar a tecnologia da impressora 3D em sala de aula, afim de motivar e demonstrar as diversas possibilidades encontradas a partir dessa ferramenta e, ainda, para estimular a criatividade dos alunos.

Nesse contexto, a parceria com as professoras regentes foi fundamental para encontrar os meios de introduzir a impressora 3D em projetos educacionais. Durante as ativid ades realizadas, pôde-se perceber o grande entusiasmo e concentração dos alunos diante das demonstrações utilizando a impressora 3D e, além disso, os benefícios para o aperfeiçoamento do aprendizado ficaram visíveis.

\section{Referências Bibliográficas}

Cliever (2019), https://www.cliever.com/.Gagné, R. M., (1971), Como se realiza a aprendizagem. Rio de Janeiro: Livros Técnicos e Científicos. Tradução: Therezinha Maria Ramos Tovar. $1^{\mathrm{a}}$ edição.

Mercado, L. P. L., (2002), Novas tecnologias na educação: reflexões sobre a prática. UFAL.

Relvas, C. A. M. (2018), O Mundo da Impressão 3d e o Fabrico Digital, 1 a edição. 